\title{
A finite element study to compare the forces generated by a newly designed NITI file with an established rotary file
}

\author{
Ajay Saxena, Manoj Chandak
}

\begin{abstract}
Aim: Aim of this study is to evaluate the lateral forces on the instrument in the apical 3rd of curved canal with two Nickel Titaniu m rotary systems.

Methodology: One brand of instrument RaCe no 25 was scanned with micro computed tomography to produce a real-size, 3-dimensional (3-D) model and was compared with Anexas (designed by authors). The stresses on the instrument during simulated shaping of the root canals were analyzed numerically by using a 3 D finite element (FE) package, taking into account the nonlinear mechanical behavior of the NiTi material.

Results: Anexas shows lowest values for force generation in the apical 3rd of canal as compared to RaCe which shows higher values.

Conclusion: With FE simulation of root canal shaping by two files, it was observed that different instrument designs would experience unequal amount of force generation in canal, as well as reaction torque from the root canal wall.

Keywords: Fin ite element analysis, NiTi rotary files, RaCe, Residual stresses, Stres s distribution
\end{abstract}

\section{INTRODUCTION}

Thanks to the extraordinary super elasticity and strength of these alloys, rotary instruments with as much as 4-fold the taper of traditional manual instruments are now available (1-3). Consistent and efficient canal shaping is now possible with relatively few instruments (3-5). The clinician who has performed endodontics has experienced a variety of emotions ranging from happiness, to an upset such as the procedural accident of breaking an instrument. During bio mechanical preparation procedures, the potential for instrument breakage is always present

Nickel-titanium (NiTi) instruments have been marked as a way to overcome the shortcomings of broken instruments in curved canals. NiTi-alloy has the advantages of super elasticity and the shape memory effect (6). Various brands of NiTi system have been introduced to the market, having a slightly different design for its cross-sectional shape, helical angle, and "radial lands" compared to each other (7). The most commonly used materials are Stainless steel and the Nickel-Titanium alloy. Root canal instrumentation has involved the use of stainless steel hand files. Investigations have shown that the preparation of curved root canals with stainless steel instruments frequently results in undesirable aberrations such as elbows and zips (8). Increasing the resistance to fracture is a prime focus in the design of new NiTi rotary systems. The design can affect the mechanical behavior of any instrument (9). RaCe files (FKG Dentaire, La Chaux-de-
Fonds, Switzerland) have a triangular cross section with positive cutting angles (25). Anexas (Cad model) is a new file design by the author, this cad design of the file is having variable pitch and variable taper, the cross section of the file is asymmetrical, helical angles are accentuated. The tip is non cutting and half spiral.

Different factors that can influence the resistance to cyclic fatigue include the diameter, metal mass, cross-sectional shape, and surface fin ish of rotary files. Another factor for the cyclic fatigue life of files is the shape at the circumference. Forces required to disrupt the molecular attraction can be decreased by providing a greater mass of rounded surface following the cutting edge of files at the circumference (11). In endodontics using the finite element method, the geometry of the structure such as the post design, material properties, along with the magnitude and direction of any kind of load can be changed easily in simulation, which is a significant advantage over experimental methods in vivo (12).

\section{MATERIALS AND METHOD Mechanical Property of NiTi}

Here in this study the nonlinear mechanical behavior of NiTi material is similar to the one reported by others (13). Briefly, the model stress-strain behavior of NiTi alloy comprises a linear elastic deformation of the austenite phase, followed by elastic and then the plastic deformation of the martensitic phase. The elastic strains and the transformation strain are mostly reversible, but the 
plastic strain is not reversible $(13,14)$ The general mechanical properties entered for the NiTi material were Young's modulus 36 gigapascals (GPa) and the Poisson's ratio is 0.3 . The critical stress at the beginning of the forward phase transformation was taken to be $504 \mathrm{MPa}$ and at the end point of recoverable strain was $755 \mathrm{MPa}$ (14).

Simu lation of the root canal (RC) shaping.

To carry out this simulation on the finite element model, a 3D-FE model was constructed for a root canal 14 mmlong with a curvature of $45-$ degree angle and $6 \mathrm{~mm}$ radius. The model canal had an apical foramen $0.25 \mathrm{~mm}$ diameter and about $5 \%$ apical taper. The behavior of the 3 brands of NiTi files was analyzed numerically in a Finite element package (ABAQUS 8.0) to simulate the bending conditions during RC shaping. Files were inserted to the full length of the simulated root canal and the stress distribution on the surface and within the instruments was evaluated. The virtual rotation rate was fixed at $240 \mathrm{rpm}$. The force exerted by file in the lateral direction was evaluated.

In the current study a brand of NiTi instrument, RaCe (size 25, 0.06 taper, FKG Dentaire) was scanned at 2 microns interval in a micro computed tomography machine (phoenix v|tome|x s S\&I - 10065) to obtain a real-size geometric configuration of the RaCe instrument. After obtaining the 3D data which was in DICOM it was converted into the STL format, the data was again converted into IgS. The noise in the 3D stack of data was suppressed digitally to create a 3D model of RaCe file.

A new file design Anexas (size 25, variable taper) which was to be tested against the existing design was constructed as the CAD model. Usually for such a study a mesh of linear, 8noded, hexahedral elements was laid over the instrument in the software to produce a 3D model for entry into FE analysis. The model for Anexas consisted of 3547 elements and 5944 nodes for RaCe 2017 elements and 4461 nodes .

\section{RESULTS}

In this study while inserting file into the simulated canal, both files experienced a force but to varying degrees along the direction of its longitudinal axis as well as a reaction on the on the surface of root canal wall this force is same as the force acting on the surface of the file. The force acting on the surface of the endodontic instrument is assessed in an engineering software ABACUS and ANSYS. The results showed that RaCe instrument showed higher value of lateral forces acting on the surface of the file as compared to the Anexas file in the apical third section. The amount of force exerted by $\mathrm{RaCe}$ was found to be 170 grams as compared to 153 grams exerted by Anexas file. The value of the force became more or less constant once the full length was reached in the simulated canal. The stress acting on the file was also analyzed. It was found that in RaCe the file experienced stress till $8.5 \mathrm{~mm}$ from the tip while the Anexas file experienced stress up to $6.5 \mathrm{~mm}$ only.

\section{DISCUSSION}

There has been a good number of articles that have been published on the application of the virtual reality technology in orthodontics (15), restorative dentistry (16), orthognathic surgery (17), and implantology (18), with quiet encouraging results. This is an effort to apply the virtual reality technology in rotary endodontics.

In the last decade NiTi rotary instruments have been gaining popularity among the general dentists and endodontic specialists. But at the same time there is an increasing concern about the instrument fracture during use, as evidenced by the amount of reports on this problem $(19,20)$ If you examine fracture instruments under electron microscope basically two types of fracture mechanis ms were identified 1) fatigue failure characterized by numerous patches of linear fatigue striation marks and 2) torsional failure characterized by the circular abrasion marks on the fracture surface $(21,22)$. Examination of the instrument longitudinally by eyes and microscopically would reveal the cause of failure (23).

But actual cause of instrument fracture could not be determined satisfactorily by such inspection of broken instruments, because it's simply impossible to assess the amount of force required to fracture this instrument or the amount of force acting on the files to cause such a catastrophe.

So a mathematical simulation is used here and estimated the stress distribution and residual stresses on the instrument. In dental research to analyze the stress of structural objects with complex morphology, strain gauge technique, and finite element method are now commonly used. Finite element analysis is now practically and broadly applied to the field of structural and mechanical analysis. In Finite Element analysis, a large structure is divided into a large number of small simple shaped elements and nodes for which individual deformation (strain and stress) can be very easily calculated than for the whole undivided large structure. By solving the complex deformation of all the small elements simultaneously and mathematically, the deformation of the structure as a whole can be assessed (24) esaily. Hence finite element analysis 
method was utilized in this study. The forces acting on file are generated as a result of friction between dentin and the cutting edge of the instruments (25).

In our study the amount of force exerted by the race file was 170 grams while the amount of force exerted by Anexas file was 153 grams. The amount of lateral forces exerted by the race file was found to be much greater as compared to that of Anexas. Similarly the force acting on the file goes upto $8.5 \mathrm{~mm}$ in race and $6.5 \mathrm{~mm}$ in Anexas file. The author has designed the Anexas file with a variable taper and variable pitch, the cross section of the file is also asymmetrical, it leads to less screwing effect of the file inside the canal due to which there is less lateral and apical forces acting on the file. This tends to less instrument breakages. Anexas file has variable helical angle which reduces the screwing tendency. All of the features combining make sure that the amount of forces acting on the file gets reduced apically as well as laterally. Keeping in mind that during the manufacture of NiTi instruments, small machining scratches and grooves are invariably left on the surface of these instruments, these surface imperfections can serve as notches that would concentrate the stress at one point, limiting the instrument's fatigue life span. The high concentration of stresses at the cutting edge of race instrument might cause these machining defects to become microcracks. Crack like features at the cutting surfaces have been a frequent observation in clinically used race instruments (26).

\section{CONCLUSION}

Within the limitations of this study, it can be easily seen that lot of stresses were generated on surface of race files compared to Anexas. The same results were seen with the forces acting on the total length of file. Race had high lateral stresses compared to Anexas. It can be easily concluded that each instrument design would experience unequal degree of screw in tendency, as well as the reaction torque from the root canal wall. There is a much difference in the location for maximum stress concentration and in the value and distribution of the residual stresses for various instrument designs, so the operator needs to analyze the cross sectional design and taper of files for their use.

\section{REFERENCES}

[1]. Walia H, Brantley WA, Gerstein H. An initial investigation of the bending and torsional properties of nitinol root canal files. J Endodon 1988; 14:346-51.

[2]. Walia H, Costas J, Brantley W, Gerstein H. Torsional ductility and cutting efficiency of the Nitinol file. J Endodon 1989;15:174 (abstract 22).
[3]. Cantatore G. Evolution des techniques d'instrumentation canalair. Eur Dent Mag Le Monde Dentaire 1998;87:11-25.

[4]. Glosson CR, Haller RH, Dove SB, del Rio CE. A comparison of root canal preparations using NiTi hand, NiTi motor-driven and KFlex endodontic instruments. J Endodon 1995;21:146-51.

[5]. Thompson SA, Dummer PMH. Shaping ability of ProFile 04 Taper Series 29 rotary nickel-titaniu $\mathrm{m}$ instruments in simulated root canals. Int Endod J 1997;30:1-7.

[6]. Walia HM, Brantley WA, Gerstein H. An initial investigation of the bending and torsional properties of Nitinol root canal files. J Endod 1988;14:346-51.

[7]. Hata G, Uemura M, Kato AS, Imura N, Novo NF, Toda T. A comparison of shaping ability using ProFile, GT file, and Flex-R endodontic instruments in simulated canals. J Endod 2002; 28:316 - 21.

[8]. Hüls mann M, Schade M, Sch $\delta$ fers F. A comparative study of root canal preparation with HERO642 and Quantec SC rotary NiTi instruments. Int Endod J 2001;34:53846.

[9]. Kim HC, Yum J, Hur B, Cheung GS. Cyclic fatigue and fracture characteristics of ground and twisted nickel -titanium rotary files. $\mathbf{J}$ Endod. 2010 Jan;36(1):147-52.

[10]. Sch€afer E, Oitzinger M. Cutting efficiency of five different types of rotary nickeltitanium instruments. J Endod 2008;34:198-200.

[11]. McSpadden JT. Mastering Endodontic Instrumentation. $1^{\text {st }}$ ed. Chattanooga, TN: Cloudland Institute; 2007. p. 51-6.

[12]. Roylance D. Finite element analysis. Material Science and Engineering, Cambridge: Massachusetts Institute of Technology; 2001.

[13]. Xu X, Eng $\mathrm{M}$, Zheng $\mathrm{Y}$, Eng D. Comparative study of torsional and bending properties for six models of nickel-titanium root canal instruments with different crosssections. J Endod 2006;32:372-5.

[14]. Wang GZ. A finite element analysis of evolution of stress-strain and martensite transformation in front of a notch in shape memory alloy NiTi. Mater Sci Eng A 2007;460 -1:383-91.

[15]. Carriere J, Carriere L. Softlanding treatment through inverse anchorage

[16]. and virtual reality. J Clin Orthod 1995;29:479-86.

[17]. Herder J, Myszkowski K, Kunii TL, Ibusuki M. A virtual reality interface to an intelligent 
dental care system. Stud Health Technol Inform 1996;29:400-

[18]. Wagner A, Rasse M, Millesi W, Ewers R. Virtual reality for orthognathic surgery: the augmented reality environment concept. J Oral Maxillofac Surg 1997;55:456-63.

[19]. Verstreken K, Van Cleynenbreugel J, Marchal G, Van Steenberghe D, Suetens P. Computer-assisted planning of oral implant surgery. An approach using virtual reality. Stud Health Technol Inform 1996;29:42334.

[20]. Ankrum MT, Hartwell GR, Truitt JE. K3 Endo, ProTaper, and ProFile systems: breakage and distortion in severely curved root of molars. J Endod. 2004(30):234-7.

[21]. Bergmans L, Van Cleynenbreugel J, Beullens M, Wevers M, Van Meerbeek B, Lambrechts P. Progressive versus constant tapered shaft design using NiTi rotary instruments. Int Endod J. 2003;36:288-95.

[22]. Cheung GSP, Peng B, Bian Z, Shen Y, Darvell BW. Defects in ProTaper S1 instruments after clinical use: fractographic examination. Int Endod J. 2005; 38:802-9.

[23]. Wei X, Ling J, Jiang J, Huang X, Liu L. Modes of failure of ProTaper nickeltitanium rotary instruments after clinical use. J Endod. 2007;33:276-9.

[24]. Cheung GSP, Peng B, Bian Z, Shen Y, Darvell BW. Defects in ProTaper S1 instruments

[25]. after clinical use: fractographic examination. Int Endod J 2005;38:802-9.

[26]. Srirekha A, Bashetty K. Infinite to finite: An overview of finite element analysis. Indian J Dent Res. 2010;21:425-32.

[27]. Schrader C, Peters OA. Analysis of torque and force with differently tapered rotary endodontic instruments in vitro. $\mathrm{J}$ Endod. 2005;31:120-3.

[28]. Abujudom DN, Thoma PE, Fariabi S. The effect of cold work and heat treatment on the phase transformations of rear equiatomic NiTi shape memory alloy. Material Science Forum. 1990;56-58:565-70. 